\title{
PRODUTIVIDADE ECONÔMICA E COMPONENTES DA PRODUÇÃO DE ESPIGAS VERDES DE MILHO EM FUNÇÃO DA ADUBAÇÃO NITROGENADA
}

\author{
FRANCISCO MOREL FREIRE ${ }^{1}$, MARIA CELUTA MACHADO VIANA ${ }^{1}$, MARIA \\ HELENA TABIM MASCARENHAS ${ }^{1}$, MARINALVA WOODS PEDROSA ${ }^{1}$, ANTÔNIO \\ MARCOS COELHO ${ }^{2}$ e CAMILO DE LELIS TEIXEIRA DE ANDRADE ${ }^{2}$
}

${ }^{1}$ Pesquisadores da Unidade Regional EPAMIG Centro Oeste, Cx. Postal 295, CEP: $35701-$ 970, Sete Lagoas, MG, Brasil,E-mail:morel@epamig.br,mcv@epamig.br; mhtabimm@ epamig.br; marinalva@epamig.br

${ }_{2}^{2}$ Pesquisadores da Embrapa Milho e Sorgo, Rod. MG 424 km 65, CEP: 35701-970, Sete Lagoas, MG, Brasil,E-mail: amcoelho@cnpms.embrapa.br; camilo@cnpms.embrapa.br

Revista Brasileira de Milho e Sorgo, v.9, n.3 p. 213-222, 2010

RESUMO - Foi avaliado, durante dois anos, o efeito de doses de nitrogênio (N) na produtividade de espigas verdes de milho e em componentes da sua produção. Cinco doses de $\mathrm{N}\left(0,60,120,180\right.$ e $\left.240 \mathrm{~kg} \mathrm{ha}^{-1}\right)$ aplicadas em cobertura foram testadas num delineamento experimental de blocos casualizados, com quatro repetições. Foram avaliadas a produção e o número de espigas comerciais com palha por hectare, peso das espigas com e sem palha, comprimento e diâmetro de espigas sem palha e relação espiga com palha/palha. Aumentos na produtividade de espigas comerciais com palha com a aplicação de $\mathrm{N}$ foram encontrados, sendo estimadas as máximas produtividades de 13,52 t ha ${ }^{-1}$ com a dose de $157 \mathrm{~kg} \mathrm{ha}^{-1}$ de $\mathrm{N}$ (primeiro ano) e de 14,86 $\mathrm{t} \mathrm{ha}^{-1}$ com a dose de 177 $\mathrm{kg} \mathrm{ha}^{-1}$ de $\mathrm{N}$ (segundo ano). Os aumentos na produtividade de espigas não foram devido aos aumentos do número de espigas por área e do comprimento destas, que não foram afetados pela adubação nitrogenada. Diferentemente da relação espiga/palha, o peso e o diâmetro das espigas foram influenciados pela elevação das doses de N. Foi proposta uma tabela de recomendação de adubação nitrogenada nos moldes de preços preestabelecidos de $\mathrm{N}$ e de espigas.

Palavras-chave: Zea mays L., doses de nitrogênio, recomendação de adubação. 


\title{
ECONOMIC YIELD AND PRODUCTION COMPONENTS OF GREEN MAIZE EARS INFLUENCED BY NITROGEN FERTILIZATION
}

\begin{abstract}
The effect of nitrogen $(\mathrm{N})$ doses on yield of the green maize ears and its production components was evaluated during two years. Five $\mathrm{N}$ doses $(0,60,120,180$ and $240 \mathrm{~kg} \mathrm{ha}^{-1}$ ) applied in topdressing were tested in a randomized block design with four replications. The efficiency of treatments was evaluated by the production and the number of commercial green ears per hectare, weight of husked and unhusked ears, length and diameter of unhusked ears and husked ear/husk ratio. Increases in husked commercial ear yield by $\mathrm{N}$ application were found, with maximum production of $13.52 \mathrm{tha}^{-1}$ estimated by $157 \mathrm{~kg} \mathrm{ha}^{-1} \mathrm{~N}$ application (first year) and of $14,86 \mathrm{tha}^{-1}$ with $177 \mathrm{~kg} \mathrm{ha}^{-1} \mathrm{~N}$ dose (second year). The increases in the production of green ears were not due to increases in the number of ears per area and by length of these. Differently of husked ear/husk ratio, the average weights of the husked and unhusked ears and diameter of unhusked ears were affected by $\mathrm{N}$ application. It was proposed a table of recommended $\mathrm{N}$ doses based on pre-established prices of $\mathrm{N}$ and commercial ears.
\end{abstract}

Key words: Zea mays L., nitrogen doses, fertilizer recommendation.

Uma das fontes de renda do agricultor da região central mineira se concentra na produção do milho para consumo "in natura" (milhoverde). Nesta região, foram comercializados aproximadamente 17.385 toneladas de espigas verdes, em 2008 (CEASA, 2009).

A cultura do milho direcionada para a comercialização de espigas verdes no período de entressafra demanda a utilização de irrigação e de um sistema de produção mais tecnificado, no qual a adubação nitrogenada desempenha papel de suma importância, estando entre os fatores que mais influenciam a produtividade dessa cultura. $\mathrm{O} \mathrm{N}$, juntamente com o K, são os nutrientes mais extraídos por essa cultura (Coelho, 2007). Assim, quando se desejam produtividades elevadas, torna-se necessário complementar a quantidade de $\mathrm{N}$ suprida pelo solo com a adubação nitrogenada (Coelho et al., 1992, Amado et al., 2002).

Vários trabalhos visando avaliar o efeito da adubação nitrogenada na cultura do milho, com foco na produção de grãos secos, têm sido encontrados na literatura, com respostas positivas (Mar et al., 2003; Shioga et al., 2004; Fernandes, 2005; Jakelaitis et al., 2005; Veloso et al., 2006; Aratani et al., 2006) e mesmo ausência de resposta (Casagrande \& Fornasieri 
Filho, 2002). Por sua vez, para a produção de espigas verdes, o $\mathrm{N}$ tem sido responsável pelo aumento do seu rendimento, sendo seu efeito influenciado também por outros fatores, como genotípicos e ambientais. Trabalhos têm demonstrado o efeito da adubação nitrogenada sobre a produtividade de espigas para consumo verde. Silva et al. (2000) encontraram produtividade máxima de $11,7 \mathrm{t} \mathrm{ha}^{-1}$ de espigas verdes comerciais com palha com a aplicação de $151 \mathrm{~kg} \mathrm{ha}^{-1}$ de N. Com adubação nitrogenada de $120 \mathrm{~kg}$ parcelada aos 25 e 45 dias, Silva \& Silva (2003) obtiveram produtividade de $10,9 \mathrm{t} \mathrm{ha}^{-1} \mathrm{de}$ espigas empalhadas. Por sua vez, produtividade mais elevada, da ordem de 21,4 t ha-1 de espigas verdes com palha, foi obtida por Cardoso et al. (2010), com a aplicação de $160 \mathrm{~kg} \mathrm{ha}^{-1}$ de N.

Para comercialização, atendendo às exigências do mercado consumidor, as espigas devem ser, entre outras características, grandes, cilíndricas e bem empalhadas. No que se refere ao papel do $\mathrm{N}$ no peso delas, Cardoso et al. (2010) verificaram que a adubação nitrogenada propiciou espiga verde por planta mais pesada, sendo a resposta quadrática, com peso máximo por espiga com palha de 445 g e de 298 g para espiga sem palha.

Pelas particularidades do N, as recomendações de suas doses para as culturas têm sido baseadas em curvas de resposta obtidas localmente. Além disso, as doses consideradas econômicas estão ainda sujeitas aos preços desse nutriente e do produto colhido. Assim, estudos para avaliar o efeito da adubação nitrogenada na produtividade e nas características comerciais da espiga e que permitam elaborar recomendações econômicas de $\mathrm{N}$ para a cultura do milho-verde fazem-se ainda necessários.

Este trabalho teve como objetivo avaliar o efeito de doses de nitrogênio aplicadas em cobertura na produtividade de espigas verdes e em componentes da sua produção, sugerindo recomendações econômicas desse elemento para a cultura do milho-verde.

\section{Material e Métodos}

O experimento foi instalado no mês de julho dos anos de 2007 e 2008, na Fazenda Experimental da Epamig, no município de Prudente de Morais, MG, Brasil, localizada a $19^{\circ} 27^{\prime} 15^{\prime \prime}$ latitude sul, 44 09'11" longitude oeste e $732 \mathrm{~m}$ de altitude. O clima da região é do tipo Aw, com duas estações bem definidas: seca (maio a outubro) e águas (novembro a abril). O solo, classificado como Latossolo Vermelho Amarelo, textura argilosa (EMBRAPA, 1999), apresentava as seguintes características químicas na camada de $0-20 \mathrm{~cm}$ : pH em água de 5,4; 4,46 $\mathrm{cmol}_{\mathrm{c}} \mathrm{dm}^{-3}$ de $\mathrm{H}+\mathrm{Al}$ $\left(\mathrm{Ca}(\mathrm{OAc})_{2}\right.$ 0,5 $\left.\mathrm{mol} \mathrm{L}^{-1} \mathrm{pH} 7,0\right) ; 0,00 \mathrm{cmol}_{\mathrm{c}} \mathrm{dm}^{-3}$ de $\mathrm{Al}^{3+}, 2,56 \mathrm{cmol}_{\mathrm{c}} \mathrm{dm}^{-3} \mathrm{de} \mathrm{Ca}^{2+}$ e $0,37 \mathrm{cmol}_{\mathrm{c}} \mathrm{dm}^{-3}$ de $\mathrm{Mg}^{2+}\left(\mathrm{KCl} 1 \mathrm{~mol} \mathrm{~L}^{-1}\right) ; 105 \mathrm{mg} \mathrm{dm}^{-3}$ de $\mathrm{K} \mathrm{e}$ 24,0 $\mathrm{mg} \mathrm{dm}^{-3}$ de P (Mehlich-1); $\mathrm{V}=42 \%$.

Dois meses antes da instalação do trabalho, no primeiro ano, foi realizada a calagem do solo, com calcário dolomítico $($ PRNT $=98 \%)$, visando elevar a saturação por bases a $60 \%$. Os tratamentos consistiram de 
cinco doses de nitrogênio $(0 ; 60 ; 120 ; 180$ e 240 $\mathrm{kg} \mathrm{ha}^{-1}$ de N), na forma de ureia, aplicadas em cobertura, divididas igualmente nos estádios V3, V6 e V9 (Coelho, 2007). O delineamento experimental foi de blocos casualizados, com quatro repetições. As parcelas foram constituídas de cinco linhas espaçadas de $1,00 \mathrm{~m}$ x 0,20 m (50.000 plantas ha $\left.{ }^{-1}\right)$, com uma área de $35 \mathrm{~m}^{2}(7,0$ $\mathrm{m} \times$ 5,0 m). Como área útil, foram consideradas as três linhas centrais, desprezando-se $1 \mathrm{~m}$ em cada extremidade.

No plantio, em todas as parcelas, foi aplicado o equivalente a $10 \mathrm{~kg} \mathrm{ha}^{-1}$ de $\mathrm{N}$ (ureia), $70 \mathrm{~kg} \mathrm{ha}^{-1}$ de $\mathrm{P}_{2} \mathrm{O}_{5}$ (superfosfato simples) e 40 $\mathrm{kg} \mathrm{ha}^{-1}$ de $\mathrm{K}_{2} \mathrm{O}$ (cloreto de potássio), sendo as recomendações das doses desses dois últimos nutrientes baseadas em resultados de análise de solo. Ainda na adubação de plantio, foi adicionado o equivalente a $50 \mathrm{~kg} \mathrm{ha}^{-1}$ de FTE. O híbrido de milho-verde utilizado foi o AG 4051.

A irrigação, do tipo aspersão convencional, foi manejada empregando-se uma planilha eletrônica (Albuquerque \& Andrade, 2001). Diariamente, dados da evaporação do Tanque Classe A e de chuva registrados na estação climatológica padrão da Embrapa Milho e Sorgo, distante 4,2 km da área experimental, foram utilizados na planilha eletrônica que estima a evapotranspiração de referência e calcula o balanço de água no solo. Valores médios de coeficiente de cultura para o milho $(\mathrm{Kc})$ foram empregados para converter a evapotranspiração de referência em evapotranspiração da cultura.
Para o caso da produção de espigas verdes de milho, adotou-se um nível de esgotamento da água do solo de $30 \%$. As lâminas de irrigação foram medidas com uma bateria de coletores instalada dentro da área experimental.

Por ocasião da colheita, a eficiência dos tratamentos foi avaliada pelas seguintes variáveis: produtividade e número de espigas comerciais com palha por hectare, peso médio das espigas com e sem palha, comprimento e diâmetro (parte mediana) de espigas sem palha e relação espiga com palha/palha. Consideraram-se como comerciais as espigas grandes, cilíndricas e bem empalhadas maiores que $21 \mathrm{~cm}$ e com diâmetro superior a $5 \mathrm{~cm}$. Os dados relativos ao peso, comprimento e diâmetros das espigas, bem como da palha, foram tomados em amostras contendo dez espigas.

Os resultados foram submetidos às análises de variância e de regressão, aceitandose os níveis de probabilidade de $5 \%$ para o teste $\mathrm{F}$ e de $10 \%$ para o teste $\mathrm{t}$. A dose relativa à máxima eficiência econômica foi obtida igualando-se a primeira derivada da equação que relaciona a produção de espigas comerciais com palha com as doses de $\mathrm{N}$ a 0,0056047 , correspondente à relação entre os preços do $\mathrm{N}\left(\mathrm{R} \$ 2,41 \mathrm{~kg}^{-1}\right)$ e de espiga ( $R \$ 430,00 \mathrm{t}^{-1}$ ) (Alvarez, 1991). Utilizando os resultados dos dois anos de trabalho, foi feita uma simulação em que doses econômicas de $\mathrm{N}$ foram estimadas com base em preços preestabelecidos de $\mathrm{N}$ e de espiga. 


\section{Resultados e Discussão}

Respostas à aplicação das doses de $\mathrm{N}$ foram verificadas no ano de 2007, para a produção de espigas comerciais com palha, sendo estimada uma produtividade máxima de 13,52 $\mathrm{t} \mathrm{ha}^{-1}$, que foi obtida com a dose de $157 \mathrm{~kg} \mathrm{ha}^{-1}$ de $\mathrm{N}$. Para o ano de 2008, foram também encontradas respostas à aplicação das doses de $\mathrm{N}$, obtendo-se uma produtividade estimada máxima de $14,86 \mathrm{t}$ $\mathrm{ha}^{-1}$, com a dose de $177 \mathrm{~kg} \mathrm{ha}^{-1}$ de N (Figura 1). Os valores dessas doses são de mesma grandeza de outros encontrados na literatura. Silva et al. (2000) obtiveram produtividade máxima de espigas verdes com palha mediante a aplicação de $151 \mathrm{~kg} \mathrm{ha}^{-1}$ de N, enquanto Cardoso et al. (2010) encontraram essa produtividade com a dose de $160 \mathrm{~kg} \mathrm{ha}^{-1}$ de N. Considerando que essas doses são relativas às produtividades de máxima eficiência física, foram também estimadas aquelas referentes à máxima eficiência econômica, obtendo-se, respectivamente, para os anos de 2007 e 2008, os valores de 136 e de $156 \mathrm{~kg} \mathrm{ha}^{-1} \mathrm{de} \mathrm{N}$.

Os aumentos na produtividade de espigas não foram atribuídos ao aumento do número de espigas por área, embora tenha se observado uma tendência de elevação da quantidade de espigas por área em resposta à aplicação de N (Tabela 1). Em Monteiro et al. (1989), Silva et al. (2000) e Silva et al. (2003), no entanto, foi constatado o efeito da aplicação de nitrogênio no número de espigas por hectare, o que pode explicar em parte o aumento na produção de espigas por área verificado nos referidos trabalhos.

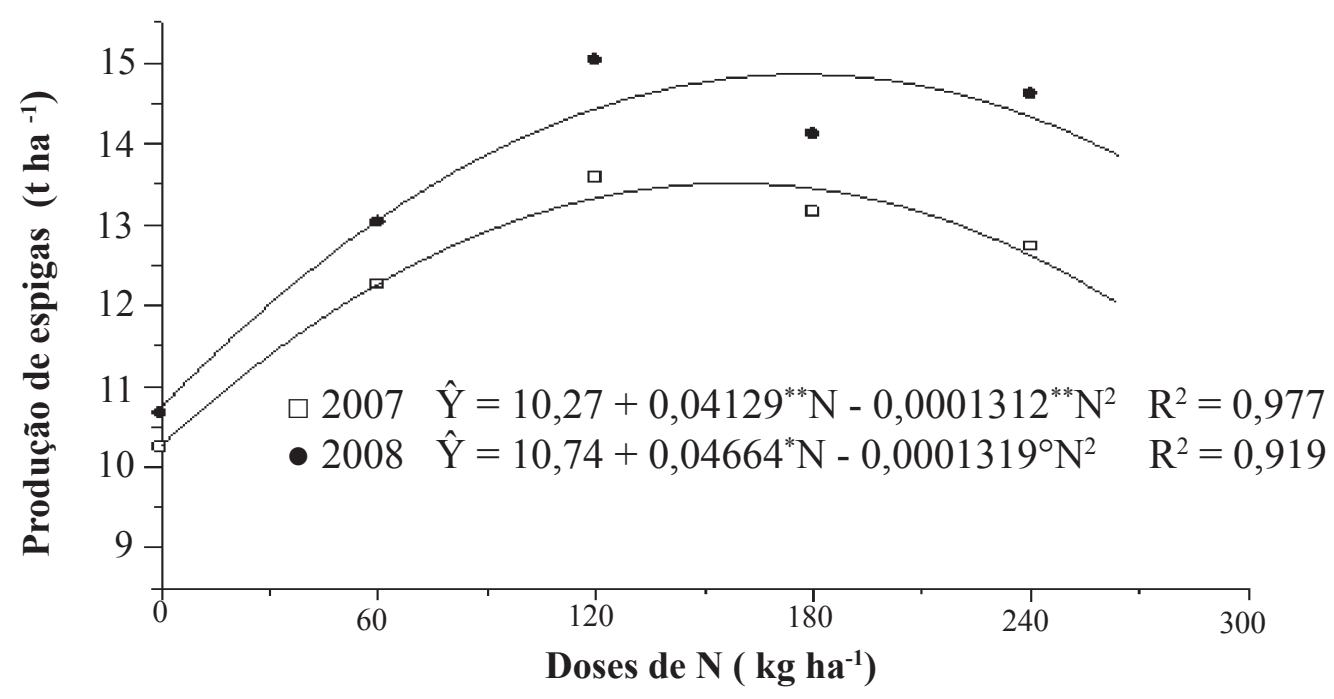

FIGURA1. Produção de espigas verdes comerciais com palha em resposta a doses de nitrogênio em cobertura, anos de 2007 e 2008. Epamig Centro-Oeste, Prudente de Morais, MG, Brasil. ${ }^{* *},{ }^{*} \mathrm{e}^{\mathrm{o}}=$ significativos a 1,5 e $10 \%$ de probabilidade, respectivamente, pelo teste $\mathrm{t}$. 
Diferentemente do número de espigas por área, que não foi afetado pelas doses de $\mathrm{N}$, o peso médio das espigas, com ou sem palha, foi influenciado pela elevação dessas (Figura 2). Pelo comportamento dessas respostas, verificou-se uma tendência de aumento do peso da palha com o incremento das doses de N. Essa tendência, por sua vez, foi confirmada quando se avaliou o efeito do $\mathrm{N}$ na relação espiga com palha/palha (Tabela 1). A informação dessa relação é considerada importante, ao dar ideia do padrão da espiga sem palha para o mercado varejista. No tocante ao comprimento da espiga sem palha, não se observou também efeito da adubação nitrogenada (Tabela 1). Diferentemente, para o diâmetro da espiga sem palha, verificou-se que as doses de $\mathrm{N}$ influenciaram significativamente essa variável (Figura 3).

No presente trabalho, infere-se que a produção de espigas de milho-verde foi aumentada devido aos incrementos nos pesos médios das espigas, uma vez que o número dessas por área não foi influenciado pela adubação nitrogenada. A esse respeito, Silva et al. (2003) e Cardoso et al. (2010) já enfatizaram o efeito positivo dessa adubação no peso das espigas de milho com e sem palha. O ganho de peso das espigas, por sua vez, não foi relacionado ao comprimento da espiga sem palha, mas ao aumento do diâmetro dessas. Possivelmente, o aumento do número de grãos na espiga (dados não avaliados no trabalho) possa também ter contribuído para explicar o aumento do peso dessas, visto que essa variável é afetada pela aplicação das doses de N (Silva et al., 2003).

Com base na equação relativa ao ano de 2007 (Figura 2) e para uma recomendação de adubação em cobertura, aplicada parceladamente, de $136 \mathrm{~kg} \mathrm{ha}^{-1}$ de $\mathrm{N}$, considerada de máxima eficiência econômica para esse ano, seriam esperadas espigas verdes de milho com e sem palha com pesos de 376,0 g e de 257,4 g, respectivamente. Pela equação da Figura 3 e considerando essa mesma dose de $\mathrm{N}$, o diâmetro da espiga sem palha seria da ordem de 49,5 mm. Possíveis diferenças

TABELA 1. Número total de espigas comerciais com palha por hectare; comprimento médio da espiga sem palha e relação espiga com palha/palha em resposta a doses de nitrogênio em cobertura, ano de 2007. Epamig Centro-Oeste, Prudente de Morais, MG, Brasil.

\begin{tabular}{cccc}
\hline $\begin{array}{c}\text { Dose de } \mathbf{~} \\
\left(\mathbf{k g ~ h a}^{-1}\right)\end{array}$ & $\begin{array}{c}\text { Número de espigas por } \\
\text { hectare }\end{array}$ & $\begin{array}{c}\text { Comprimento da espiga } \\
\text { sem palha (cm) }\end{array}$ & $\begin{array}{c}\text { Relação espiga com } \\
\text { palha/palha }\end{array}$ \\
\hline 0 & 44833 & 18,1 & 3,29 \\
60 & 43500 & 19 & 3,29 \\
120 & 47000 & 18,8 & 3,19 \\
180 & 46500 & 19 & 3,15 \\
240 & 46000 & 18,9 & 2,96 \\
\hline Valor F & $1,766^{\text {ns }}$ & $1,993^{\text {ns }}$ & $0,975^{\text {ns }}$ \\
\hline
\end{tabular}

$\overline{\mathrm{ns}}=$ Não significativo. 
- Espiga com palha $\Delta$ Espiga sem palha

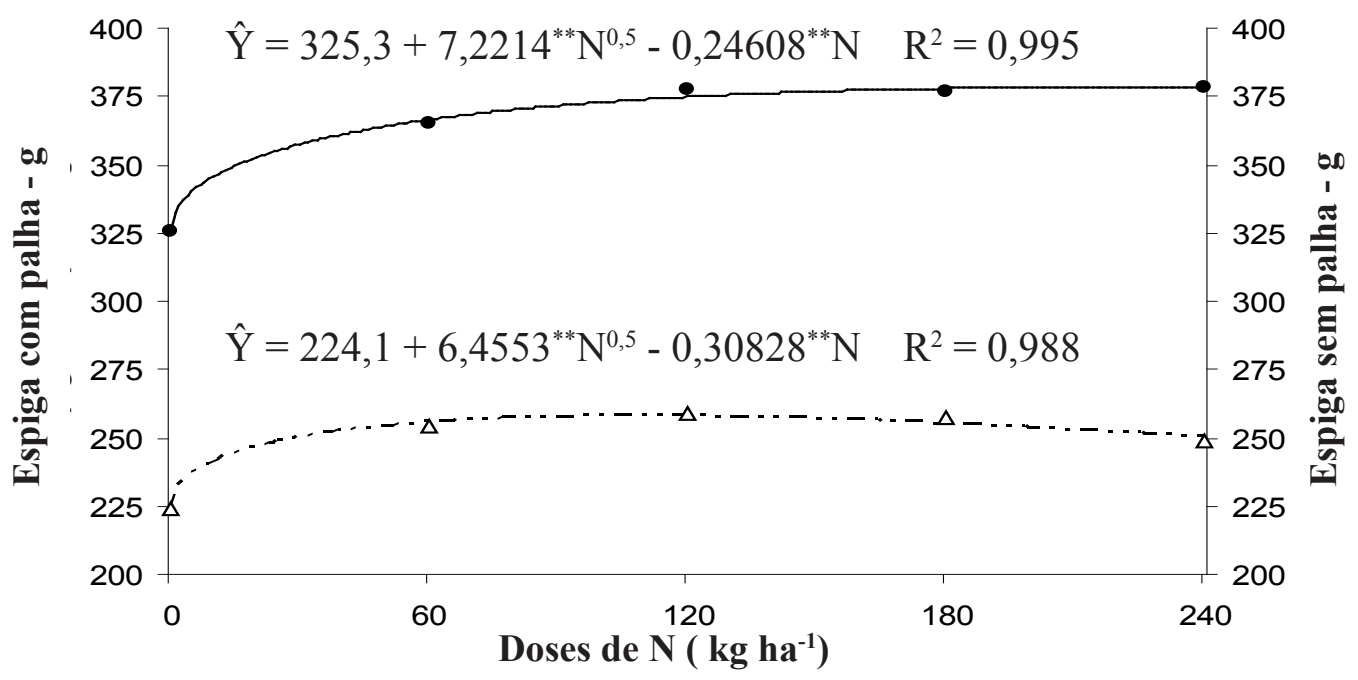

FIGURA 2 . Peso médio das espigas com e sem palha em resposta a doses de nitrogênio em cobertura, ano de 2007. Epamig Centro-Oeste, Prudente de Morais, MG, Brasil. ${ }^{* *}=$ significativo a $1 \%$ de probabilidade pelo teste $\mathrm{t}$.

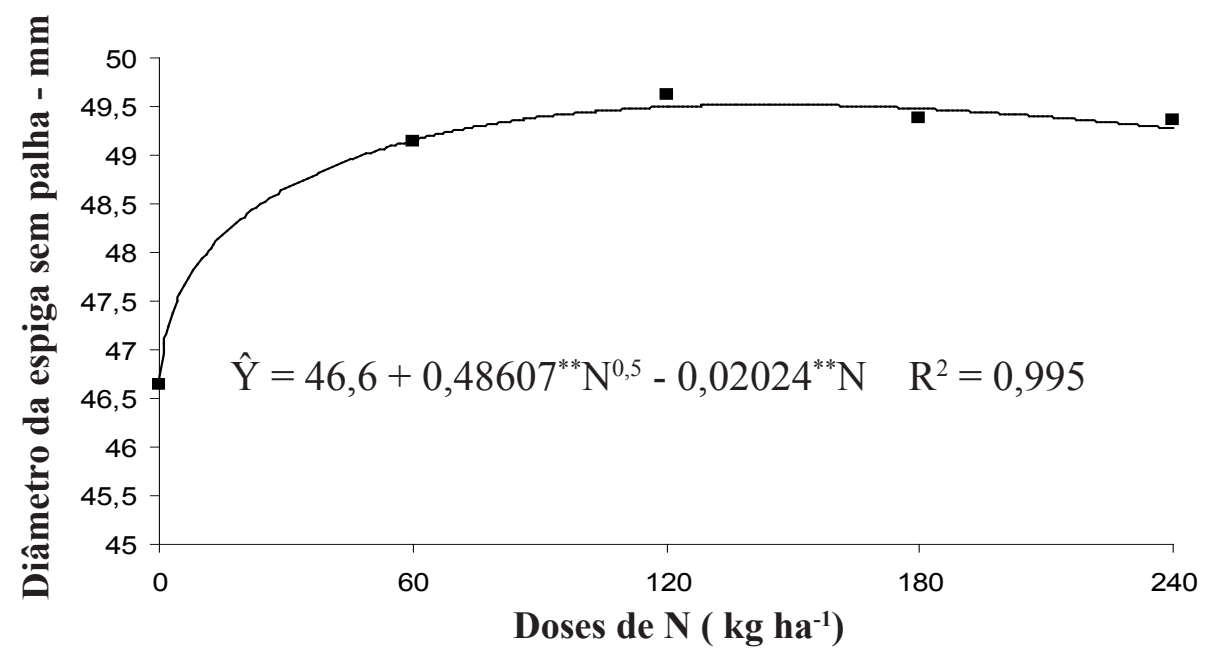

FIGURA 3. Diâmetro médio de espigas sem palha em resposta a doses de nitrogênio em cobertura, ano de 2007. Epamig Centro-Oeste, Prudente de Morais, MG, Brasil. ** $=$ significativo a $1 \%$ de probabilidade pelo teste $\mathrm{t}$. 
de resultados, quando comparados com os de outros trabalhos, como o de Cardoso et al. (2010), devem-se a fatores ambientais e genéticos do material testado.

Sabe-se que a dose de $\mathrm{N}$ a ser recomendada para a cultura do milho pode variar durante $\mathrm{o}$ ano, em função da taxa de mineralização, do teor de matéria orgânica e da lixiviação do nitrato no solo e, em especial, pelo valor da precipitação pluvial no período de sua condução (Jaynes \& Colvin, 2005 apud Veloso et al., 2006). Além disso, na recomendação de adubação nitrogenada, há que se considerar ainda o lado econômico, devendo-se levar em conta os preços do nutriente $\mathrm{N}$ e das espigas de milho. Como os preços do $\mathrm{N}$ e das espigas podem oscilar durante o ano em função do mercado, depreende-se que a cada alteração dos seus valores novas doses de $\mathrm{N}$ devem ser calculadas.
Pela metodologia de igualar a primeira derivada da equação que relaciona a produção de espigas dessa cultura com as doses de $\mathrm{N}$ aplicadas a um valor correspondente à relação entre os preços do $\mathrm{N}$, e das espigas verdes de milho, pode-se, então, calcular as novas quantidades de $\mathrm{N}$ que variam de maneira contínua. Assim, com o intuito de ajudar o produtor na tomada de decisão de quanto adubar, em termos de $\mathrm{N}$, a cultura do milho-verde no período de inverno, na região central mineira, é proposta uma tabela, apresentando doses médias desse nutriente, nos moldes de preços preestabelecidos de $\mathrm{N}$ e de espigas (Tabela 2). Verifica-se que, à medida que os preços do $\mathrm{N}$ decrescem e os das espigas verdes de milho aumentam, maiores quantidades desse insumo são recomendadas. De maneira inversa, com a elevação dos preços do $\mathrm{N}$ e redução dos das espigas, doses menores de $\mathrm{N}$ são indicadas.

TABELA 2. Doses médias de $\mathrm{N}$ recomendadas em cobertura para a cultura do milho-verde em função dos preços do N e da espiga verde com palha. Epamig Centro-Oeste, Prudente de Morais, MG, Brasil.

\begin{tabular}{|c|c|c|c|c|c|c|c|c|c|}
\hline \multirow{3}{*}{$\begin{array}{c}\text { Espiga } \\
\text { verde } \\
\left(\mathrm{R} \$ \mathbf{k g}^{-1}\right)\end{array}$} & \multicolumn{9}{|c|}{$\mathbf{N}\left(\mathbf{R} \$ \mathrm{~kg}^{-1}\right)$} \\
\hline & 1,70 & 2,00 & 2,30 & 2,60 & 2,90 & 3,20 & 3,50 & 3,80 & 4,10 \\
\hline & \multicolumn{9}{|c|}{ 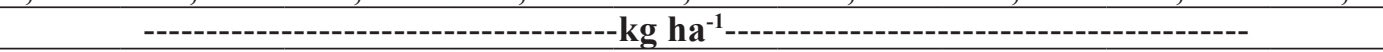 } \\
\hline 1,20 & 162 & 160 & 160 & 159 & 158 & 157 & 156 & 155 & 154 \\
\hline 1,10 & 161 & 160 & 159 & 158 & 157 & 156 & 155 & 154 & 153 \\
\hline 1,00 & 160 & 160 & 158 & 157 & 156 & 155 & 154 & 152 & 152 \\
\hline 0,90 & 160 & 158 & 158 & 156 & 155 & 154 & 152 & 151 & 150 \\
\hline 0,80 & 159 & 158 & 156 & 154 & 154 & 152 & 150 & 149 & 148 \\
\hline 0,70 & 158 & 156 & 154 & 153 & 152 & 150 & 148 & 146 & 145 \\
\hline 0,60 & 156 & 154 & 152 & 150 & 148 & 147 & 145 & 143 & 141 \\
\hline 0,50 & 154 & 152 & 150 & 148 & 145 & 143 & 140 & 138 & 136 \\
\hline 0,40 & 151 & 148 & 145 & 142 & 140 & 136 & 134 & 131 & 128 \\
\hline 0,30 & 146 & 142 & 138 & 134 & 130 & 126 & 123 & 119 & 115 \\
\hline 0,20 & 135 & 129 & 124 & 118 & 112 & 106 & 100 & 95 & 89 \\
\hline 0,10 & 102 & 91 & 80 & 68 & 57 & 45 & 34 & 23 & 11 \\
\hline
\end{tabular}




\section{Conclusões}

A adubação nitrogenada além de propiciar aumentos na produção de espigas verdes comerciais, ao elevar o peso e o diâmetro delas, contribui positivamente para a melhoria do valor comercial do produto. Os aumentos na produção de espigas, por sua vez, não foram relacionados aos aumentos do número de espigas por área e dos comprimentos dessas.

As doses de $\mathrm{N}$ a serem recomendadas para aplicação em cobertura na cultura do milho-verde variam de maneira contínua, em função dos preços desse nutriente e das espigas.

\section{Agradecimentos}

À Fundação de Amparo à Pesquisa do Estado de Minas Gerais (FAPEMIG), o apoio financeiro e a concessão da bolsa BIPDT.

\section{Literatura Citada}

ALBUQUERQUE, P. E. P.; ANDRADE, C. L. T. Planilha eletrônica para a programação da irrigação de culturas anuais. Sete Lagoas: Embrapa Milho e Sorgo, 2001. 14 p. (Embrapa Milho e Sorgo. Circular Técnica, 10).

AMADO, T. J. C.; MIELNICZUK, J.; AITA, C. Recomendação de adubação nitrogenada para o milho no RS e SC adaptada ao uso de culturas de cobertura do solo, sob sistema plantio direto. Revista Brasileira de Ciência do Solo, Viçosa, MG, v. 26, n. 1, p. 241-248, 2002.

ARATANI, R. G.; FERNANDES, F. M.;
MELLO, L. M. M. Adubação nitrogenada de cobertura na cultura do milho irrigado, em sistema plantio direto. Revista Científica Eletrônica de Agronomia, Garça, v. 5, n. 9, 2006.

ALVAREZ V., V. H. Avaliação da fertilidade do solo (superfícies de resposta - modelos aproximativos para expressar a relação fatorresposta). Viçosa: Imprensa Universitária - UFV, 1991. 75p.

CARDOSO, M. J.; SILVA, A. R.; GUIMARÃES, L. J. M.; PARENTONI, S. N.; SETUBAL, J. W. Produtividade e espiga verde de milho sob diferentes níveis de nitrogênio. Horticultura Brasileira, Brasília, DF, v. 28, n. 2 (Suplemento - CD Rom), p. S3786-S3789, 2010.

CASAGRANDE, J. R. R.; FORNASIERI FILHO, D. Adubação nitrogenada na cultura do milho safrinha. Pesquisa Agropecuária Brasileira, Brasília, DF, v. 37, n. 1, p. 33-40, 2002.

CEASA Minas. 2009. Informações de mercado. Procedência de produtos, ofertas e preços. Período consolidado: milho-verde. Belo Horizonte. Disponível em: <http://www.ceasaminas.com. br>. Acesso em 13/04/2009.

COELHO, A. M.; FRANÇA, G. E.; BAHIA FILHO, A. F. C.; GUEDES, G. A. A. Doses e métodos de aplicação de fertilizantes nitrogenados na cultura do milho sob irrigação. Revista Brasileira de Ciência do Solo, Campinas, v. 16, p. 61-67, 1992.

COELHO, A. M. Manejo da adubação nitrogenada na cultura do milho. Sete Lagoas: Embrapa Milho e Sorgo, 11p. (Embrapa Milho e Sorgo. Circular Técnica, 96), 2007.

EMBRAPA-CentroNacionaldePesquisadeSolos. Sistema brasileiro de classificação de solos. Brasília: EMBRAPA, Rio de Janeiro, 1999. 412p. 
FERNANDES, F. C. S. Efeitos de níveis de nitrogênio na produtividade de seis cultivares de milho (Zea mays L.). Revista Científica Eletrônica de Agronomia, Garça, v. 4, n. 7, 2005.

JAKELAITIS, A.; SILVA, A. A.; FERREIRA, L. R. Efeitos do nitrogênio sobre o milho cultivado em consórcio com Brachiaria brizantha. Acta Scientiarum. Agronomy, Maringá, v. 27, n. 1, p. 39-46, 2005.

MAR, G. D.; MARCHETTI, M. E.; SOUZA, L. C. F.; GONÇALVES, M. C.; NOVELINO, J. O. Produção do milho safrinha em função de doses e épocas de aplicação de nitrogênio. Bragantia, Campinas, v. 62, n. 2, p. 267-274, 2003.

MONTEIRO, M. A. R.; COSTA, E. F.; GHEIY, H. R.; PINTO, J. M. Níveis de nitrogênio e lâminas de irrigação no rendimento do milho verde. Pesquisa Agropecuária Brasileira, Brasília, DF, v. 24, p. 741-749, 1989.

SHIOGA, P. S.; OLIVEIRA, E. L.; GERAGE, A. C. Densidade de plantas e adubação nitrogenada em milho cultivado na safrinha. Revista Brasileira de Milho e Sorgo, Sete
Lagoas, v. 3, n. 3, p. 381-390, 2004.

SILVA, P. S. L.; DINIZ FILHO, E. T.; GRANJEIRO, L. C.; DUARTE, S. R. Efeitos de níveis de nitrogênio e da aplicação de deltametrina sobre os rendimentos de espigas verdes e de grãos de milho. Revista Ceres, Viçosa, MG, v. 47, p. 75-87, 2000.

SILVA, P. S. L.; OLIVEIRA, F. H. T.; SILVA, P. I. B. Efeitos da aplicação de nitrogênio e densidades de plantio sobre os rendimentos de espigas verdes e de grãos de milho. Horticultura Brasileira, Brasília, DF, v. 21, p. 452-455, 2003.

SILVA, P. S. L.; SILVA, P. I. B. Parcelamento da adubação nitrogenada e rendimento de espigas verdes de milho. Horticultura Brasileira, Brasília, DF, v. 21, p. 150-153, 2003.

VELOSO, M. E. C.; DUARTE, S. N.; DOURADO NETO, D.; MIRANDA, J. H.; SILVA, E. C.; SOUZA, V. F. Doses de nitrogênio na cultura do milho, em solos de várzea, sob sistema de drenagem subterrânea. Revista Brasileira de Milho e Sorgo, Sete Lagoas, v. 5, n. 3, p. 382-394, 2006. 